\title{
Miranda
}

Revue pluridisciplinaire du monde anglophone /

Multidisciplinary peer-reviewed journal on the English-

speaking world

19 | 2019

Rethinking Laughter in Contemporary Anglophone Theatre

\section{Textures and Layers of Sound: An Interview with Marcus Fischer}

Interview

Alice Clapie

\section{CpenEdition}

\section{Journals}

Electronic version

URL: http://journals.openedition.org/miranda/21152

DOI: $10.4000 /$ miranda. 21152

ISSN: 2108-6559

\section{Publisher}

Université Toulouse - Jean Jaurès

\section{Printed version}

Date of publication: 7 October 2019

\section{Electronic reference}

Alice Clapie, "Textures and Layers of Sound: An Interview with Marcus Fischer", Miranda [Online], 19।

2019, Online since 11 October 2019, connection on 16 February 2021. URL: http://

journals.openedition.org/miranda/21152 ; DOI: https://doi.org/10.4000/miranda.21152

This text was automatically generated on 16 February 2021

\section{(c) (i) $\Theta()$}

Miranda is licensed under a Creative Commons Attribution-NonCommercial-NoDerivatives 4.0 International License. 


\section{Textures and Layers of Sound: An Interview with Marcus Fischer}

Interview

Alice Clapie

\section{Biography}

This interview followed Marcus Fischer's third performance at the Whitney museum in New York for the 2019 biennial. Marcus Fischer is a musician and multimedia artist from Portland, OR. He creates immersive and intimate soundscapes with tape loops, found objects, field recordings and live instrumentation. 
Fig. 1

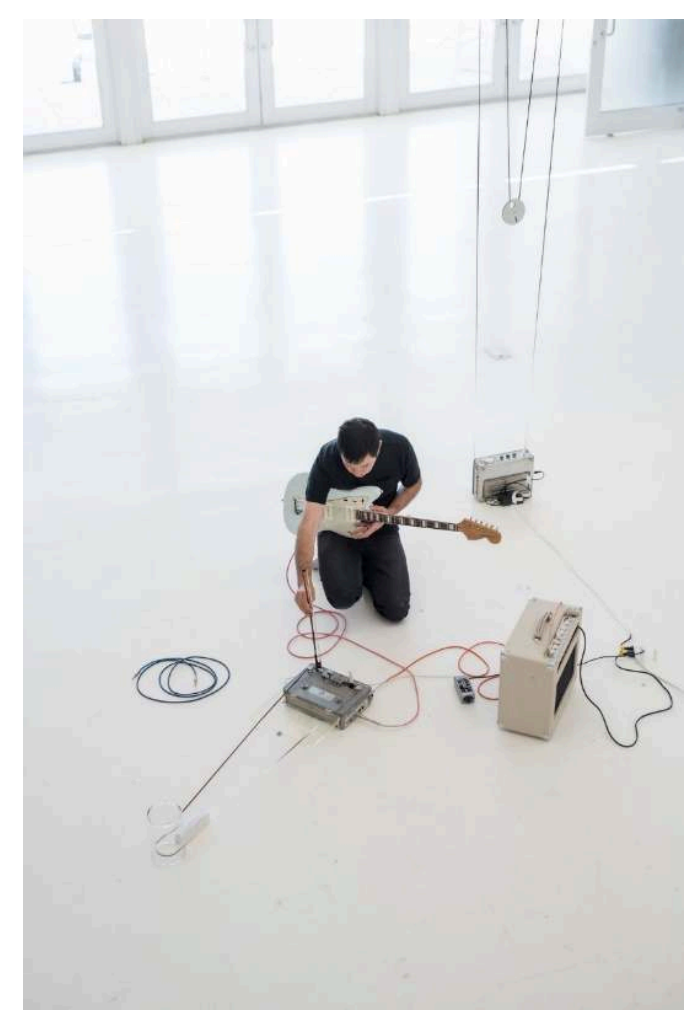

Poucher, Mark. "Marcus Fischer at The Rauschenberg Residency." The Whitney Museum. WEB. URL: https://whitney.org/events/marcus-fischer

\section{Interview}

Alice Clapie: Marcus Fischer, I'd like to start with a very broad question? What is art for you?

Marcus Fischer: Art for me is any kind of creative expression. I mean, I feel like it's not necessarily bound by discipline or medium.

A.C.: Can you come back on the origins of your art? How did it all start? What are your influences?

Marcus Fischer: Yes, I've been playing music since I was a teenager, I was playing in bands, making music on my own. I think that my art in its current form comes a lot out of that background from playing and performing music by myself and in group settings. And then, I have just a curiosity about sound: in the way sound is a physical force. It's not just what you're hearing, it's what you're feeling too, in the way, you know, we can manipulate recorded medium through changing speeds and textures and all that. So, it's just been an ongoing evolution of a few simple ideas.

A.C.: Your vision of sound is very interesting! I was particularly interested in the elements that you used to produce sound which are not very common of course. So, magnetic tapes, found objects, field recordings all that, how do you come with these associations? How do you find them and how do you come to create something with it?

Marcus Fischer: Yes, I think it's all through experimentation and listening. So, listening is something that's really important to me as far as when I am working on something new, just trying different things out and trying to find what the soul of that sound can be. In my performance that night that you saw I used a bunch of 
different things that I've utilized in the past. It was kind of almost like a distillation of a lot of different things that I've been doing. So, there was the guitar and playing the guitar in alternate ways, not just strumming it or picking it, it was like playing the body of instrument and listening to the resonance of that. That comes just through listening and kind of feeling those sounds and thinking about how you can activate one object or an instrument with another. So, I was playing the guitar while tuning forks through the pick-ups of the guitar or using that bamboo brush to create chiming sounds. And then there's also, like, that little speaker that I had that was vibrating the seed pods. That's something that came from an installation that I did last March at the Variform Gallery in Portland which was a whole installation of twelve speakers that were all vibrating these types of shells. And, you know, it's just listening to the texture of that and all of these things. The textures are really important to me, almost more important than melody and rhythm. It's like... texture!

A.C.: The word that comes to my mind is organic. It's very organic. The feeling that I had watching the performance was that it was synchronized not with the room per se but with what was happening outside the room and we could see through this glass wall. So, the view of the sun setting on the Hudson River, it seemed, synchronized with your performance and, I don't want to say that it was natural because I hate that word, but it all came very naturally

Marcus Fischer: Yeah, yeah, so what was interesting was that the night before I performed in this same room. It was a concert for the blind and low-vision members of the community. So, it was a smaller audience and as I started that performance a storm started to blow in. There was thunder and lightning, but that room is so isolated from the outside with these big windows you couldn't hear the thunder. As I was performing I was looking out the window, at the weather coming in and the change of light and really started performing to the weather on the outside and, as the performance ended, it completely cleared up and you could see New Jersey again. It was just like this beautiful synchronized activity. It was kind of like I was improvising with a force that wasn't my own. So, my performances are primarily improvised. I have some certain things that I know I'm going to do but how I get from one place to the next is all through improvisation. So, I really enjoyed that feeling of responding to what was on the other side of the window. I was focusing on that a bit at that performance that you saw. So, I was kind of trying to follow the arch of the sun being high and there were kind of brighter sounds. Then as the performance went on there was more this kind of low end, low frequency sounds that were coming in as it was getting darker. And then I was using the tape spindle that was spinning in the center of the room, bringing it up and then lowering it back down, like the sun was setting. So, it was kind of like just playing with the elements that I had brought with me and then the ones that existed in the room already and kind of letting one respond to the other in that way.

A.C.: That is really the feeling that had watching the performance and it was stunning, I really appreciated it!

Marcus Fischer: Oh thanks!

A.C.: I had a question about tape loops! How does that work exactly? Because that tape loop going up and down was sort of the centerpiece of your performance and it was hypnotizing in a way! So, where does this idea come from and how does it work exactly?

Marcus Fischer: Yeah, so I've been using recording tapes in my music since the very beginning. My father had a lot of tape recorders around the house. So, I was always 
experimenting with them recording one tape into another one or several into the same and so as a way of layering sound. I think I got my first reel to reel tape recorder in the mid-1990s and I had read about some of the early music concrete experiments that were going on. So, I started playing with splicing tapes, different recordings. At first I was just mostly using the recordings that were on the tapes, because, you buy a tape at a thrift store and it would have, you know, some Glenn Miller and different recordings on there and I could cut them up and turn it around so it'd be backwards and everything. So, it was just that physical manipulation of that material that was so interesting to me. And then the idea of repetition by making loops was also fascinating. As I started to utilize them more for live performances I realized that, if I engaged the architecture of a space by stretching these loops out longer and longer -- because first I was using them on the floor and I had my microphone stand on one side of the room and had my tape recorder on the other, but you could only get so far -- so then I realized that oh vertical you could get so much more time that you could record. So, what I'm doing primarily is that I have a tape recorder set up so it's always recording and I can control from my mixing board what sound can be sent to the tape recorder and when they come back around you'll hear them again as it's been repeating. So, I can start layering layers and layers of sound by however how many times the same piece of tape passes through the machine. So, I can kind of build up a kind of a dense underbed for what I am playing on top of. And it is a little bit tricky because if I hit a bad note or make a mistake, that piece will come back around again and you'll hear it again so it won't let you forget if you've made some sort of mistake.

A.C.: But it's improvisation so there are no mistakes! It's something that comes along, right?

Marcus Fischer: Right, right yeah and then so there are other choices. When I know that sound is coming back around I can either try to put something louder on top of it to try to bury it or I can try to do the same thing again so that it starts a new motif based on that unintended...

A.C.: During the performance you passed along recordings of the voice of a woman for people to listen to individually or I saw some people listening to it together, and it was very intimate. Where did that recording come from?

Marcus Fischer: So there was... actually each of these tape recorders that I passed round the room had a different set of sounds on it. So, you might have gotten the one with the voices, somebody else might have gotten sounds of those seed pods very close up just shuffling them in my hands and another one got some very slow down piano. So, it was just three different machines that had different loops but, I don't know, it was just something that I wanted to do as far as bringing the sounds that I had in the space were all spatialized so I was able to move the sounds around through the different speakers. I could control that through my setup. Depending on where you were your experience was very different. It was almost like you had a private concert that you could hold in your hand. So, that experience was very different. The tapes in the Walkman were anywhere from twenty seconds to three minutes. So, you would get a different set of sounds and the person next to you passed it along so...

A.C.: Do you expect the audience to experience your performance as a group or as individuals? Because often we say that in a theater the audience is conscious of being a group and people look at each other and they know that they're here together. But now that 
you are talking about the fact that everyone can have a different experience of your performance, what do you expect them to feel?

Marcus Fischer: Yeah, I would like it to be something that is experienced as a group but sound has a really interesting quality to it where -- especially when you don't quite know what you're hearing -- your brain based on your individual experience will kind of fill in the blanks as far as sounds... So, for example, if I use found sound, a field recording it could just be white noise from an old record player or something but to you it might sound like the ocean which might make you think about the time when you were seven years old and you took a family trip to the coast and it was raining. So, the sounds that I use in the performances, I'm trying to let people see what all the sound sources are as I am creating them. I start with nothing and then I am building up these layers of sound with the things I have in front of me. But then there are certain sounds that I introduce that are disembodied from the sources that you see. That ones are being often field recordings or found sound and I feel like, at that point, it's up to the individual's interpretation of what those things might be. So, I think you come and experience it as a group: people sitting on the floor, people sitting in a circle, it's quite intimate. And then your individual life experience will kind of dictate some of the things that you are imagining if that makes sense? Memory, your senses: all of those things work together in order to create your own sensory experience.

A.C.: That was the third work that you were presenting for the Whitney biennial and this one had no title whereas the two previous ones had one! Why is that?

Marcus Fischer: I don't tend to title my performances. So, often I'll refer to it on a later date by either the date and place where it took place or sometimes in a description of what was happening at that time. So, if I have put out CDs of live work and sometimes I won't say like "Live performance at X and X place at Los Angeles" you know, I'll just say like "the one where the bus drives at the end" or "the one where we all sat in a circle" or something like that.

A.C. Yes, it's pretty much: "here and there, what's happening."

Marcus Fischer: Yes. Because I don't know what's going to happen before it happens, I wouldn't give it a name before it's finished.

A.C.: Right, well initially pieces of music were not titled at all. It's only recently that musicians started to title their music.

Marcus Fischer: Right, right, yeah.

A.C.: And so, you create musical works and performance works, in what ways are these two approaches different and/or complementary for you?

Marcus Fischer: I think that they're similar as far as my musical practice is the same based on the tools that I use but they're very different when you look at the end result. With my recorded material, it takes much longer for me to get something finished because I record passages and I'll edit and I'll edit and I'll edit and I'll cut more of it away until what's left are the things that need to be there. It's a subtractive process. So, I'm taking away whereas my performance tends to be additive. I'm starting with nothing and I'm building something up. With the recordings it takes an arch: I'm creating and then I'm subtracting. Performance is just additive. Things are happening, I'm introducing more elements. I might take some away but something else takes its place. 
A.C.: Do you feel like you could make something perfect and finished when you're creating recorded material and this would not be the case with performance if that makes sense?

Marcus Fischer: Yeah, I mean, perfection is a word that is a weird one for me because I feel like I don't ever want something to be perfect. I feel like imperfections are often the most interesting parts of something. I just view them as being two different things. It's not like I can do one thing in one medium and not the other. I could imitate my recorded material in a live setting, that would be fairly easy but that would maybe be much less interesting for myself and for the viewer. I have released live performances as recorded materials too. So, I feel like there's a dialogue between the two, but I just prefer to treat them differently.

A.C.: Do you think it is important to go see performances and to perform today?

Marcus Fischer: Yeah, I do. I think it's very important. I feel like there's a lot of, you know the things that are just kind of lost by people having access to a lot of technology. I have a friend who... I'll invite him to go to a performance and he'll wind up looking up that person's performance on YouTube and then deciding whether or not he wants to go. And you know it's totally different! Somebody's cellphone video on YouTube is not going to take the place of experiencing it in person. There's no substitute I think for experiencing a live performance.

A.C.: What do you think people can get out of experiencing a performance? Why do you think people need to go see a performance?

Marcus Fischer: I think there's the intimacy that you get from being in the same space as somebody creating something. Especially somebody creating something in a spontaneous way. Because, that would never exist the same way again. It would be completely different to the person who saw it the next day or the day before. And that kind of thing [performance]: you can put your phone down and you just experience the thing as it's happening. That part, I just feel like there's no substitute for that. And then also to support artists creating work especially now that it's getting harder and harder for people to find funding for producing their projects. Showing up and supporting people is the best way to allow us to continue and present work that might be coming up.

A.C.: Final question: after the Whitney biennial what's next?

Marcus Fischer: In September I'm doing two nights of performance with Laura Ortman who's also in the biennial. She's coming to Portland's Institute for Comtemporary Arts Time Based Art Festival that happens every September. So, she and I will do some improvised performances in early September. Then right after that I'm leaving to go to Iceland to perform at a music festival there. And then to the UK to perform four or five shows.

A.C.: Great! So many more performances. Hopefully you will come back to New York!

Marcus Fischer: Oh I'd love it! I hope I will be invited back some time soon.

A.C.: Thank you very much for answering my questions! Thank you for your time.

M.F. Thank you! 


\section{ABSTRACTS}

Interview with Marcus Fischer after his performance at the 2019

Interview avec Marcus Fischer après sa performance à la biennale du Whitney Museum à New York en août 2019.

INDEX

Keywords: Marcus Fischer, Whitney Biennial, music, performance

Mots-clés: Marcus Fischer, biennale du Whitney, musique, performance

Subjects: Theater

\section{AUTHOR}

\section{ALICE CLAPIE}

Ph.D. Student

Columbia University in the City of New York ac4595@columbia.edu 